\title{
REPROBLEMATISING LANGUAGE (IN) EDUCATION IN THE PHILIPPINES: A MULTIDISCIPLINARY PERSPECTIVE
}

\author{
${ }^{1}$ Paolo Miguel M. Vicerra \& 2 Jem R. Javier \\ ${ }^{1}$ City University of Marikina \\ ${ }^{2}$ Department of Linguistics, University of the Philippines Diliman \\ (jemroquejavier@gmail.com)
}

\begin{abstract}
This paper calls for an interdisciplinary approach to policy formulation regarding the language of education in the Philippines. It has been long agreed upon that for the students to comprehend pieces of instruction, the medium of instruction is important. Continually shifting policies among three important languages has born different outcomes. However, given their high linguistic diversity, communities in the Philippines have become even more multilingual and multicultural. Constant and rigorous dynamics among the members of these communities has made some of these policies démodé since most of their research database has been exclusively between education and language studies. The bases for the formulation of policies on the language of the education system are the test-results-based outcomes on learning based on experimental settings and sometimes on the advocacies of particular groups. There is indeed a call for other perspectives from different fields and methodologies to contribute to the formulation of the language policy. It is on this note that this study attempts to integrate different social sciences in (re)discovering methodologies toward the possible encompassing determination, or non-determination, of a medium(s) of instruction.
\end{abstract}

Keywords: language education, medium of instruction, Philippine society and culture, sociolinguistics

\section{Introduction: Language (in education) and the formation of public policy}

Policy as a term is broad and may contain various definitions. But policy, especially that which was formulated by the state, is important to understand as it affects particular groups of individuals being its primary stakeholders. 
Policies can be defined as, "...statements that prescribe courses of actions in organisations" (Midgley, 2000:3). This can serve as the schematic of how a government would take actions toward a goal that it desires for the benefit of the society.

Policy making is a daunting task, for the policy that would be formed should have encompassed the three factors which serve as the major stakeholders: (1) the society and the socio-economic conditions being the climate in policy making; (2) the political system, under which involve the institutions, attitudes, and processes; and (3) public policy (cf. Fig.1). These three factors interact with each other and can therefore largely affect how policies are to be created. Theoretically and pragmatically, if one or two sides of the tripartite are/are compromised in the policy to be created, the latter would collapse as it would fail to serve its purpose of catering to the needs of the society.

It has long been agreed upon within the issues of Philippine education that the language or the medium of instruction is important to attain an understanding of contents and proficiency of the students. The debates since the American occupation has rested on three primary concerns: (1) the language the students should learn; (2) the language that would ensure what they are supposed to learn in that setting; and (3) the other social and political functions of education (Bernardo, 2007). Based on these matters, one could see that there has been at least one aspect of policy formulation within these debates. There is a clear intervention of policy makers because of a particular goal that is thought to be of importance for the stakeholders, who are the students primarily.

Fig.1. The Political System (adapted from Dye (1987: 6)).

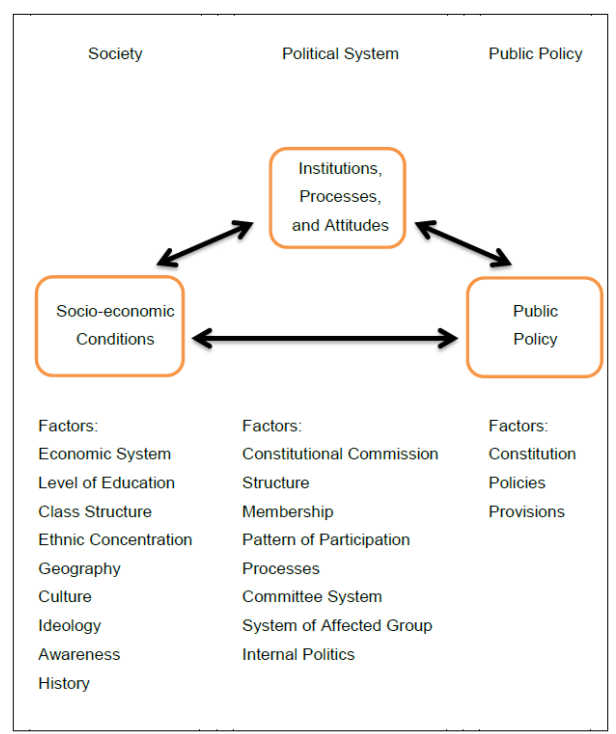


The rationale for the continually shifting policies in between three languages is that they bear different outcomes. On the one hand, English is pushed because it is the international lingua franca, which may pave the way towards economic security. On the other hand, Filipino is promoted to form a national culture which will strengthen nationalism and henceforth forge solidarity within the society (Jubilado, 2004). A third perspective meanwhile carries a multilingual approach that would somehow preserve the multicultural background of the country since the students will be trained on using the vernacular.

Within these debates is a seemingly limited view that research is almost exclusively between education and language studies. The basis for the formulation of policies on the language of the educational system are the testresults-based outcomes on learning based on experimental settings and sometimes on the advocacies of particular groups.

This paper aims to attend to the need for an interdisciplinary approach to formulating policies on the language of education in the country. There are various facets of Philippine social reality that may give direction to an integrative approach to policy decisions. These facets can be addressed by employing perspectives from different disciplines coupled with linguistics and language studies.

For our purposes, the topic of inquiry is the medium of instruction in the education system. This may include language proficiency but, this is one possible outcome and this by no means limits the research. Proficiency in a language is exclusive from successful learning. This paper, however, will explore the integration of various social sciences toward the possible encompassing determination, or non-determination, of a policy for the medium of instruction.

\section{Glimpses on the development of language policies in Philippine education}

The climate of conflicting policies on which language should be used in the classroom is indeed highly emotionally-charged (Garcia, 1996). More often than not, each side has the assumption that when a person learns in Filipino or English, he would be more vulnerable to the other. But this is countered by Phillipson (1992) who claims it to be a subtractive fallacy. Concentrating on one language would not exactly refer to a decline in the usage of another, as both languages could be learned simultaneously.

The bilingual policy in the Philippine education, which was first coded in 1974 (Jubilado, 2008), and then later reiterated in 1987, demonstrates an 
inclination to Filipino: "Filipino shall be the language of literacy and the language of scholarly discourse while English shall be maintained as the international language and the non-exclusive language of science and technology" (Garcia, 1996: 78). Meanwhile, higher education institutions are mandated to lead in the intellectualization of Filipino in the country.

However, the poor performance of students especially in subjects which are taught in English caught the interest of linguists and policy makers. Eventually, scholars moved from the limited bilingual education framework. Some advocated the use of multilingual approach with multiliteracies as a component of the paradigm (Nolasco, 2009; Bernardo, 2007; and CaniesoDoronila, 1989).

This has led to the implementation of the Department of Education Order no.74, s.2009, which institutionalises the multilingual education policy, as supported by the Congress of the Republic of the Philippines. Based on the premise that learning in one's mother tongue would significantly increase a student's performance, the order states that the medium of instruction in primary school would be the student's native language, while Filipino and English would serve as auxiliary mediums of instruction. During secondary school, the inverse should take place: the mediums of instruction would be Filipino and English while the student's mother tongue would serve as the auxiliary metalanguage. However, studies that serve as grounds for this advocacy solely equate its efficiency with academic achievement, which present results of better performance in mathematics, science, and social studies (Canieso-Doronila, 1989).

\section{Evaluation and responses corollary to language policy assessments}

Assessments on the learning capabilities of students have been undertaken to see if they perform well in school. Linguists would correlate these results to the language being used in the exam: that if the test taken were written not in the maternal language of the child, the child would perform poorly in the exam; and if the test was in the mother tongue of the student, he/she will excel in whichever subject he/she would take. However, as Bialystok (2001) states:

"The assumptions that intelligence is an attribute of individuals, that it can be quantified, and that tests can reveal the relative position of one person against some hypothetical standard have been responsible for countless injustices against individuals and dangerous misconceptions about groups. The 
fatal flaw in the argument is in the equation of performance on an intelligence test and a statement about the intelligence of an individual." (p.184)

\section{Through the eyes of the students}

Capitalising from the abovementioned facts, Vicerra and Javier (2010) conducted a research study focusing this time on the motivation for language learning and enhancement, since there is a lack of inquiry on this matter. For them, "...[a]cademic achievement does not identify how students appreciate what they are learning. It does not indicate their motivation for learning because understanding a course does not entirely mean a person is motivated" (p.2). There are studies on the motivation for education in general in the context of the Philippines, but it does not cover that of language education (Pagalilauan, 1992; Parungao, 2003). Bialystok (2001) mentions that children may perform well or poorly at school; however, "...it is not clear that differences in either direction reflect levels of intellectual capacity or are attributable to bilingualism" (p.184).

Even studies on motivation and attitude tend to gauge success based on proficiency tests and scales; and this study focused only on second language success and would not be sufficient in a multilingual society such as the Philippines (Javier and Vicerra, 2010; Lambert and Gardner, 1972).

\section{Results from the workplace}

Related to the view of an instrumentality of language learning is the 1988 study by Guzman, et al. on language proficiency and needs in higher education and the workplace. It views that language programs would be deemed effective if the language users would meet the demand of both the academe and the subsequent field of work. Proficiency in English and Filipino were tested for the purpose of associating with the participants' perceived proficiency. Their views on both languages were also scaled to determine how they viewed the adequacy of their curriculum to address the needs of their professions.

The study by Guzman, et al. again presented a results-based view; results being on the planned work of the individuals. But it offered an important factor that the language learners' thoughts and views on what they are learning are important for policy considerations. The learners, after all, are the ones directly involved. 


\section{Alternative (approach to the) bi-/multilingual education policy}

Malicsi's vision of a multilingual education is a bit different from the Mother Tongue-Based Multilingual Education (MTBMLE). In his prefatory remarks on his 2006 Multilingual conceptual glossary of Elementary Math and Science in English, Filipino, Magindanaoan, Maranao, and Tausug, Malicsi points out that the said material "...redefines and explains the English terms in English, being the official medium of instruction for these subjects, but adjusts the English to what can more readily be understood by a Filipino learner" (p.ii), thus helping the teachers and students of the said subjects "...to cope with the linguistic difficulties of an education system in a multilingual society" (p.ii).

The lexicographic work does not wish to translate all of the instructional materials used in teaching Elementary Math and Science. What it wishes to yield is the ability of the students to grasp the actual meaning of the technical and nontechnical terms in whichever language they can comfortably use for them to be able to put the lexical items into context. In fact, the explanation of terms in the glossary is not limited to the vernacular; rather, they are still explained in English with the Philippine languages as supplementary.

Some scholars believe that strengthening the foundation of the foreign language (to be used as the medium of instruction) would be more beneficial to the students. It has been noticed that even though bilingual education is employed in the Philippine education system with emphasis on Filipino and English, nevertheless, teaching the two mentioned languages to primary and secondary school students does not yield good results. Edwards (1994) has observed that "schools have often done a poor job... Traditional classes, with their emphasis on grammar and writing skills, have made the learning of languages a passive, receptive matter for students; the activity lies in the teaching" (p.192).

For this reason, apart from the multilingual glossary, Malicsi (2011) has also called for a restructuring of the English curricula in Philippine education. Instead of translating instructional materials which are usually taught in English into the mother tongue, as envisioned by the MTBMLE, he suggests that renovating the way educators teach the English language (which is the second language of a significant number of Filipino students) would be more practical. 


\section{Resurrecting the bilingual education policy?}

The question would then come to mind with regards to the manner in which the students will be taught of the second language in a satisfactory manner. Citing Edwards (1994), "[t]he chief development is to encourage a more 'natural' conversational interplay" (p.192). This is reminiscent of Celce-Murica and Larsen-Freeman's 1983 statement that not only should English teachers teach the pedagogical grammar of the language, but, teachers should also be flexible to the constant linguistic changes brought about by the international community that uses English as the lingua franca. A radical change in the way second language (i.e., English) is taught can foster abler students in the future. The cost of these developments is even more inexpensive than translating all of the textbooks and teaching materials in the maternal language of every student in the multilingual, multicultural archipelago.

Such vision is echoed in Vicerra and Javier's 2010 study conducted in Malabon City, National Capital Region, for most of their respondents mentioned that Filipino (mother tongue of most of the respondents) is attributed to identity and this is the reason for using and studying it. English, together with their view on foreign languages, is very different. Since such languages are not perceived to be part of culture and identity; the reason and the purpose for learning these languages vary.

According to the study, the reason for learning English for one is its use for travel and work prospects. It is the international standard to know English for advancements in the professional level. Unlike in Filipino, learning English has tangible and practical entailments. This was supported by the results of the study regarding the aspects of learning the students perceive that they need; particularly public speaking and writing reports and compositions. According to the authors,

"These are performative undertakings that support their practical reasons for wanting to learn the language. They are performative as against to emotive (i.e., the reason for learning a local language is that it conveys one's thought because it is "his/her" language) because these are actual skills that they can utilise once they are a part of the working population." (p.9)

The seemingly alternative view of the Bilingual Education Policy vis-àvis the MTBMLE also has its research-based grounds. Garcia (1996), for instance, points out that it is in Filipino that students learn more and faster, as 
opposed to English. We must notice that the author speaks of Filipino and English languages of instruction, and he cites Gonzalez (1996) in saying that, constitutionally, vernaculars may be used only as an auxiliary language in classroom discourse. That Filipino be used as a partner medium of instruction to English is based on the results of Garcia's 1996 study stating that,

"Of all the Philippine languages Filipino is the most widely understood and spoken. The latest survey shows that $87 \%$ of Filipinos use Filipino, 38\% in their homes. The use of Filipino for teaching will enable the student to think logically and process their experiences in a rational way." (p.80)

\section{Linguistic diversity of the Philippines and the subtractive fallacy}

Xenos (2011) has observed that the relationship between the ethnolinguistic identity and homeland in the milieu of archipelagic Philippines has become all the more difficult to establish because a large part of the population has created a complicated situation due to constant instances of the diaspora. In turn, this resulted in a coalescence of two or more ethnic groups. He discusses two migration processes that are reflected by the geography of ethnicity in the Philippines:

"...one is the diffusion of minority populations outward from their traditional and most recent territories, and the other is the intrusion or invasion into those home territories of the majority populations and sometimes of other minorities as well" (p.2).

In the Philippines, the said migration processes bring about an increase in the diversity of languages and, consequently, a decrease in the diversity of identity among the ethnolinguistic groups that happen to juxtapose, if not merge in a geographic area.

The opening, for instance, of Isla de Carabao in the province of Romblon (Southern Luzon) to the global market by being a tourist destination has brought about drastic changes within the island and its demographic makeup (Javier, 2011). They are manifested by the laying of an international airport, building of hotels and restaurants, establishment of resorts, and eventually, a sudden influx of migrants and visitors from all over the Philippines and abroad. 
For this reason, most, if not all residents of Isla de Carabao are multilingual. Each of them can speak Inonhan, the mother tongue of the island; aside from that, they know how to speak in not less than two of the following: Tagalog or Filipino, English, Cebuano, Bisaya, Romblomanon, Kinaray-a, Loocnon, Hiligaynon, Aklanon, and others.

Many things contributed to the multilingualism of the locality and its residents. In Busay Elementary School, for instance, not all of the teachers are originally from the island. Most of them do not know how to speak Inonhan which is why they use Filipino or Bisaya in conversing with their students. In teaching, they use Filipino and English, as mandated by the Philippine Constitution. Since those teachers have already been living in Isla de Carabao, their family, especially the children, are forced to study Inonhan for them to be able to socialise with the townsfolk. However, they still have not forgotten the language that they had used before migrating to the island.

Aside from these observations, Javier (2011) has figured out that Inonhan is one language that stays firmly grounded despite the relatively small number of its speakers (less than 10,000) and the impending alterations to the locality brought about by tourism and diaspora. The people of Isla de Carabao were able to adapt to these changes in their linguistic milieu not by shelving their mother tongue, but by being multi lingual for them to be able to engage themselves in intra and inter-municipal discourse.

\section{Implications for language policy making in the Philippine setting}

We have seen from the discussions above the development of the policies concerned with the language in education in the Philippines. That this has been changing from time to time proves that the issue is far from being resolved. This paper has presented some of the factors that are often, if not constantly neglected in the formation of policies for the betterment of Philippine education. Studies from different disciplines of the social sciences have created a picture of the milieu of the Philippines, from its linguistic diversity down to the people's perceptions and attitudes toward language and education.

Motivation and attitude toward languages as mentioned in this study are important to be inquired. This is because learning and the subsequent and relevant result of using a preferred language in school may cause students to learn efficiently. This is because their preferences in language may indicate how much they would want to accommodate regarding learning. There would 
be less rejection and apprehension from learning if their preference would be taken into consideration; therefore better learning would ultimately take place.

The multilingual situation of the Philippines does not necessarily call for a multilingual form of instruction as a response. As do most of the multilingual communities in the world (Nettle and Romain, 2000), most Filipinos regard multilingualism as an achievement: the emblematic language is not forgotten, yet lingue franche and other inter-societal languages are also learned to expand their geographic, political, and social reach.

\section{References}

Atienza, M.E. (1996). Ang pulitika sa paggawa ng palisi ng wika [The politics in the making of language policy]. In Constantino and Atienza (Eds.), Mga piling diskurso sa wika at lipunan [Selected discourses on language and society]. Quezon City: University of the Philippines Press.

Bernardo, A. (2007). Language in Philippine education: Rethinking old fallacies, exploring new alternatives amidst globalization. In T. Ruanni Tupas (Ed.), (Re)making society: The politics of language, discourse, and identity in the Philippines, 1-26. Quezon City: University of the Philippines Press.

Celce-Murcia, M. and D. Larse-Freeman. (1983). The grammar book: An ESL/EFL teacher's course. Massachusetts: Newbury House Publishers.

Dye, T.R. (1987). Understanding public policy. Englewood Cliffs, NJ: Prentice Hall.

Estigoy-Arzadon, M. (2011). The Mother Tongue-Based Multilingual Education (MLE) Policy - Two years after. Paper presented during the National Conference on Research in Teacher Education, 20-21 October, UP College of Education.

Garcia, E.A. (1996). The language policy in education. In M.L. Bautista (Ed.), English is an Asian language: The Philippine context: Proceedings of the Conference held in Manila on August 2-3, 1996. NSW Australia: The Macquarie Library Pty. Ltd.

Gonzalez, A. (1996). Using two/three languages in Philippine classrooms: Implications for policies, strategies and practices. Journal of Multilingual and Multicultural Development, 17(2-4), 210-218.

Guzman, M., et al. (1998). Living Language: assessment of language proficiency and needs in the professions and the work-place. Quezon City: Office of Research Coordination, University of the Philippines. 
Javier, J. (2011). Dayalektolohiya ng Wikang Inonhan sa Isla de Carabao, Romblon [The dialectology of Inonhan in Carabao Island, Romblon]. Paper presented during the Isang Araw ng Pagtalakay sa Wikang Filipino ng Unibersidad ng Pilipinas-Diliman [Forum on the Filipino Language used in the University of the Philippines Diliman], Faculty Center, UP.

Jubilado, R. (2004). Philippine linguistics, Filipino language, and the Filipino nation. Jati Journal of Southeast Asian Studies, 9, 43-54.

Jubilado, R. (2008). The Filipino Language in the Malaysian linguistic space. Jati Journal of Southeast Asian Studies, 13, 147-158.

Malicsi, J. (Ed.). (2006). A multilingual conceptual glossary of Elementary Math and Science in English, Filipino, Magindanaoan, Maranao, and Tausug. Davao City: EQuALLS, Save the Children Federation in cooperation with The Classics Foundation.

Malicsi, J. (2011). English language proficiency. Paper presented at the Conference on Language Teaching: Issues and Concerns, Pasay City, Philippines.

Nettle, D. and S. Romaine. (2000). Vanishing voices: The extinction of the world's languages. Oxford: Oxford University Press.

Nolasco, R. (2009). 21 Reasons why Filipino children learn better while using their Mother Tongue: A primer on Mother Tongue-based Multilingual Education (MLE) and other issues on language and learning in the Philippines. Guro Formation Forum.

Rafael, R. and Rosario, F. (2011). On language shift and revitalization: the case of Pangasinan. Paper presented at the International Conference on Humanities, Penang, Malaysia.

Vicerra, P. (2011). Philippine population and language in Education: Education system implications. Paper presented during the National Conference on Research in Teacher Education, 20-21 October, UP College of Education.

Vicerra, P. and J. Javier. (2010). Mashed media: attitudes of secondary school students towards English, Filipino, and their mother tongue. Paper presented at 15th English in Southeast Asia Conference, University of Macau, Macau SAR China. 